atmosphoric sciences at the University of Washington, Seattle. Within the compass of its 300 pages or so, the book contains some highly compressed information on a wide range of topics. The discussion of atmospheric motions, however, on all but the smallest turbulent scale is withheld for a subsequent volume.

There are seven chapters dealing with gravitational effects; the properties of atmospheric gases; the properties and bohaviour of cloud particles; solar and terrestrial radiation; turbulent transfer and its application to such things as nocturnal cooling and fog formation; geomagnetic phenomena and the propagation of olectromagnetic and sound waves, including a section on the radiation and blast offects of nuclear explosions.

Inevitably some topics are sketchily dealt with, and, less satisfactorily, references to original papers are few and confined to footnotes. At the end of each chapter, however, are listed the relevant text-books to which the roader must go for deeper treatment of the subject.

There is a breathlossness about this book which suggests that the authors have attempted too much, as indeed they had to if they were to live up to the title and at the same time keep the publication within manageable size. The attempt has been a gallant one, however, and there is much of value within its pages, both to those who are new to the subject and to those in need of refreshment.

As is usual with this series, the book is handsomely produced and almost entirely free from printing errors.

R. F. JONES

Advances in Upper Atmosphere Research

Papers presented at the NATO Advance Study Institute at Corfu, July 1960. Edited by B. Landmark. Pp. vii + 340. (London and New York: Pergamon Press, 1963. Published for and on behalf of Advisory Group for Aero. nautical Research and Development, North Atlantic Treaty Organization.) $80 s$. net.

THIS book is a compendium of papers presented at the NATO Advance Study Institute held at Corfu during June-July 1960. As is so often the case, a good deal of the freshness is removed by the fact that nearly threo years elapsed before the book appeared. In a subject which is now advancing very rapidly this is a serious delay. For example, three of the earlier papers are concerned with the results of the Argus experiments, matters of topical interest at the time but now put in the background by the Starfish high-altitude hydrogen bomb explosion of July 1962.

The 21 papers covor a wide range of subjects concerned with the upper atmosphero. They are collected in oight groups each of which concludes with a discussion which is summarized in the text. The subjects of the groups are, broadly, solar-terrestrial relations, effects of the Argus high-altitude explosions, recombination processes in the ionosphere, waves in plasmas, opties of the upper atmosphere, the $F$-layer, whistlers, scattering from the ionosphere and auroral ionization and solar activity and polar cap absorption.

The presentation is clear, and there is a considerable amount of useful material in the book, even though some is rather uncritically presented and some is out of date.

The prico is somewhat high for the individual purchaser, but this seems to be a feature of publications of conferences and symposia.

Harrie Massey

\section{Encyclopedia of Physics}

Edited by S. Flügge. Vol. XLI/2. Beta Decay. Pp. vi+117. (Berlin: Springer Verlag, 1962.) 49 D.M.

7 HE study of $\beta$-decay has always been associated with the investigation of nuclear structure as well as that of the $\beta$-interaction itself. Its implications for nuclear structure, as well as a description of the techniques generally used, are described in other volumes of the hand-book, so that the authors are free to eoncentrate on the experimental work bearing on the $\beta$-interaction itself, theory again being dealt with in a further volume. The impetus which the discovery of the non-conservation of parity in weak interactions in 1957 gave to the elucida. tion of the $\beta$-interaction has made this a very appropriate time to review the subject. The historical development is not neglected, there being an invigorating account of experiments designed to check the nature of $\beta$-particles and the reality of neutrinos, and also on the spectral shapes and decay constant of allowed and forbidden decays. However, a good part of the volume is given over to a description of experiments on $\beta$-recoil, a strong section on the measurement of the helicity of $\beta$-particles and neutrinos and a critical examination of the experiments on the neutron decay. Finally, the authors gather together all the evidence to determine the character and magnitude of the $\beta$-interaction, but end on the cautionary note that the experiments are still not accurate enough to establish the interaction as pure $V-A$ within quite large limits.

A surprising omission in the otherwise rather complete discussion of the observation of the helicity of $\beta$-particle is that of the double-scattering experiments of Chase and Cox thirty years earlier. A feature of the book is the inclusion of a large number of diagrams of the apparatus of key experiments; $\beta$-spectrometers themselves are, however, dealt with in yet another volume.

This is not only a work of reference within its specified limits, it is also a very readable account of experimental work in this field.

P. E. Cavanigit

\section{Electroluminescence and Related Effects}

(Advances in Electronics and Electron Physics, Supplement 1.) By Henry F. Ivey. Pp. xiii + 276. (Now York and London: Academic Press, 1963.) $88 s$.

R. H. F. IVEY has written a review of exceptional length on a subject which must rank among the untidiest in physics. So many variables have been introduced in the search for economically useful electroluminescence, both in preparing material and in exciting it, and again in seeking correlations with other luminescent behaviour and with elementary electronic properties, that the length comes as no surprise. The author does not hide the difficulties and inconsistencies abounding in the subject, though they often roduce him to brief summaries, side by side, of the key findings of several investigations of nominally the same effect with little or no comment on the contradictions thus rovealed.

Half Electroluminescence and Related Effects is deroted to zinc sulphide, the material the efficiency of conversion of electrical energy to optical energy of which may be high enough for widespread application. The vital roles of activators, particularly copper and manganese, and of co-activators, particularly chlorine, open this half, followed by considerations of the electrical conditions and temperature, and an account of time effects. The mechanism of excitation, preparatory to the emission processes, is discussed with a sense of proportion that only someone with a wide experience of the subject could hope to achieve; but, even so, no clear picture emerges.

Attention switches to other materials in the third quarter of the book. For some of them, injection lumin. escence at metal-semiconductor interfaces and aeross $p-n$ junctions dominates and is better understood. The discovery of laser action in gallium arsenide diodes occurred after the review was written; it would have made an interesting addition to this section without requiring serious modification to anything already included.

The last quarter of the book is devoted to the many influences electric fields exert on excited phosphors, beginning with the Gudden and Pohl effect, the first of many transient effects. Later studies showed many complexities, with trapped electrons generally playing 